\title{
Increase in Circulating Basement Membrane Antigens in Diabetic Rats and Effects of Insulin Treatment
}

\author{
J. Risteli*, K.E. Draeger ${ }^{1}$, G. Regitz ${ }^{1}$ and H.P. Neubauer ${ }^{1}$ \\ Max-Planck-Institut für Biochemie, Martinsried bei München, and 'Hoechst AG, Frankfurt am Main, FRG
}

\begin{abstract}
Summary. The serum concentrations of two recently discovered antigens derived from basement membranes (7-S collagen and laminin P2) were assayed in streptozotocin-diabetic rats as possible indicators of basement membrane metabolism. The concentrations of both increased significantly after 8 weeks of diabetes, and that of 7-S collagen at least remained elevated up to 24 weeks. Treatment with insulin, which did not
\end{abstract}

correct the metabolic disturbances, inhibited the increase in the concentration of 7-S collagen in serum, but did not completely normalize that of laminin P2.

Key words: Basement membrane, 7-S collagen, laminin P2, streptozotocin diabetic rats, insulin treatment.
Thickening of the capillary basement membrane is a characteristic lesion in long-term diabetes and is considered to be the ultimate cause of diabetic microangiopathy [1]. Good control of blood glucose levels is believed to inhibit the development of microangiopathy, but there is no definite proof, partly because of the lack of suitable methods for studying basement membrane metabolism [2].

Basement membranes are extracellular matrices widely distributed throughout the body. They serve as major filtration barriers and as supporting boundaries between mesenchymal and ectodermal or endodermal tissues [3]. They consist mainly of collagenous (type IV collagen) and non-collagenous proteins [3].

The recently established macromolecular structure of type IV collagen consists of four triple helical molecules of type IV collagen crosslinked to each other through a disulphide-rich 7-S collagen domain [4,5]. This domain can be solubilized from basement membranes by proteases without loss of antigenicity, and material cross-reacting with it is released into the circulation during normal basement membrane metabolism in vivo [6]. A major non-collagenous glycoprotein of basement membranes is laminin [7], which is composed of several subunits connected to each other by disulphide bridges. These disulphide-bonded regions can be isolated as dis-

\footnotetext{
* Present address: Department of Clinical Chemistry, University of Oulu, Finland
}

tinct antigenic fragments $\mathrm{P} 1$ and $\mathrm{P} 2$ after treatment with pepsin [8].

Specific and sensitive radioimmunoassays have recently been developed for measuring 7-S collagen and laminin P2 in rat serum [6]. The purpose of the present study was to apply these new methods to monitoring possible changes in basement membrane metabolism during streptozotocin diabetes in rats.

\section{Materials and Methods}

\section{Animals}

Three complete experiments were performed. They were all started when the rats were about 8 weeks of age to minimise the effects of age on the concentrations of basement membrane antigens in the circulation [6]. The rats were fed on a commercial diet ad libitum and allowed free access to the water.

In experiment 1 (Table 1) male Ivanovas rats were used. Diabetes was induced by a single injection of a freshly prepared solution of streptozotocin $(50 \mathrm{mg} / \mathrm{kg}$ body weight) given into tail vein. At 4 week intervals, starting 4 weeks after induction of the disease, 10 control rats and 10 diabetic rats were subjected to the analysis (except for the 24week group, which contained eight controls and ten diabetic animals).

In experiment 2 (Table 2) male Wistar rats were used. Diabetes was induced as in experiment 1 , but using $70 \mathrm{mg}$ of streptozotocin $/ \mathrm{kg}$ body weight. Some of the diabetic rats were treated with insulin (long-insulin, Hoechst), which was injected subcutaneously, one-third of the daily dose being given in the morning and two-thirds in the late afternoon. The other rats received $0.9 \% \mathrm{NaCl}$ instead of insulin. In this experiment four groups of animals were made: $\operatorname{controls}(n=10)$, diabetic $(n=18)$, diabetic treated with $0.9 \mathrm{IU}$ of insulin daily $(n=12)$ and diabetic treat- 
Table 1. Effect of long-term diabetes on the concentration of 7-S collagen in serum

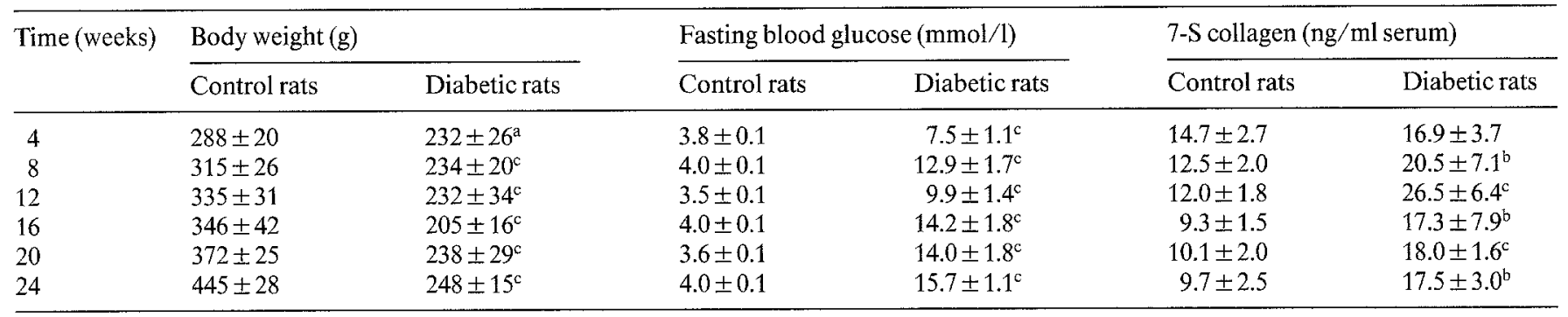

Values are expressed as mean $\pm \mathrm{SD}$.

All the diabetic rats had glycosuria $(0.5-0.9 \mathrm{~g} / 24 \mathrm{~h})$.

Significance levels were assessed using Student's t-tests 1 or $2:^{\mathrm{a}}<0.05,{ }^{\mathrm{b}}<0.01$ and $^{\mathrm{c}}<0.001$.

Table 2. Effect of insulin treatment on the concentration of 7-S collagen in serum

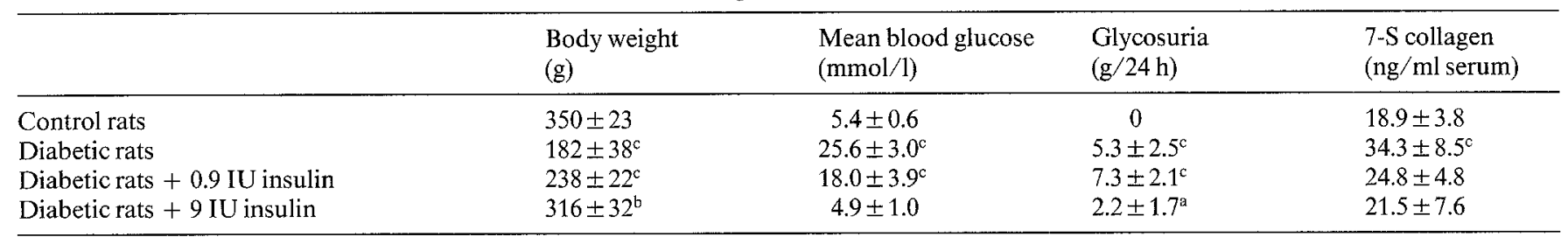

Values are expressed as mean \pm SD. Significance levels were assessed using one-way analysis of variance and Student's $t$-test $3:{ }^{\mathrm{a}}<0.05{ }^{\mathrm{b}}<0.01$ and ${ }^{\mathrm{C}}<0.001$ compared with control rats

ed with 9 IU of insulin daily $(n=18)$. The animals were killed after 8 weeks.

In experiment 3 (Fig. 1) male Wistar rats were used. Diabetes was induced and some of the animals treated with insulin as described in experiment 2 . The rats were divided into three groups: controls ( $n=$ $10)$, diabetic $(n=19)$ and diabetic treated with 9 IU of insulin daily $(n=19)$. The rats were killed after 8 weeks.

\section{Analytical Methods}

The metabolic situation was monitored in all experiments by collecting 24-h urine samples and determining glycosuria with the hexokinase method using a commercial test kit (Boehringer-Mannheim, FRG). The samples for the blood glucose determinations were drawn from the tail vein and the glucose was assayed by the hexokinase method. In experiment 1 , fasting blood glucose was determined after a 24 -h fast (Table 1). In experiment 2 , the mean blood glucose level was calculated from the area of a $7-\mathrm{h}$ glucose profile based on five determinations (Table 2). The samples for the 7-S collagen and laminin $\mathrm{P} 2$ assays were collected by cardiac puncture after 24 -h fasting.

\section{Radioimmunoassays}

The mouse 7-S collagen and laminin P2 were purified from a transplantable murine EHS tumour-producing basement membrane material [4, $8]$. The antigens were labelled with ${ }^{125} \mathrm{I}$ by the chloramine $\mathrm{T}$ method. The antisera were raised in rabbits as described previously $[4,7,8]$. In the radioimmunoassay (sequential saturation type) $0.1 \mathrm{ml}$ of the antiserum at a dilution capable of binding $50 \%$ of labelled antigen was incubated overnight at $4{ }^{\circ} \mathrm{C}$ together with $0.2 \mathrm{ml}$ of non-labelled standard antigen solution or an aliquot of the unknown sample. After adding $10000 \mathrm{cpm}$ (about $1 \mathrm{ng}$ ) of the labelled antigen, incubation was continued for $6 \mathrm{~h}$. The free and bound fractions were then separated by precipitation, using the second antibody method with goat antiserum to rabbit immunoglobulin G. All dilutions were made in phosphate-buffered saline ( $\mathrm{pH} 7.2$ ) containing $0.04 \%$ Tween 20 to prevent non-specific binding and $0.02 \%$ sodium azide to prevent bacterial growth. The antiserum dilutions (range $1: 5000$ to 40000 ) contained $0.5 \%$ of normal rabbit serum as a carrier. Non-specific binding of the labelled antigen to the carrier was in the range $1 \%-4 \%$. About $5 \mathrm{ng} / \mathrm{ml}$ of the standard antigen gave $50 \%$ inhibition in the assays used. The coefficient of variation within the assay was $2 \%-10 \%$ and that between the assays $15 \%-25 \%[6]$. All the samples from one experiment were assayed simultaneously.

\section{Statistical Methods}

The statistical significance of the differences between the means was calculated using Student's t-test (test 1). If the standard deviations of the groups differed significantly $(p<0.05)$ a modification of the t-test (test 2) was used [9]. A oneway analysis of variance was used in experiments containing more than two groups and the significance of the differences between the groups tested using a modified t-test (test 3) and calculating the critical $t$ value by the Bonferroni method [10].

\section{Results}

The changes in the serum concentrations of the 7-S collagen were monitored in long-term diabetes for 24 weeks (Table 1). A significant increase was found after 8 weeks, and the diabetic rats had $64 \%-121 \%$ more $7-S$ collagen in serum than the controls. The total amount of 7-S collagen decreased slightly with advancing age in the control rats, as observed previously [6]. The dose of streptozotocin used ( $50 \mathrm{mg} / \mathrm{kg}$ body weight) induced a diabetic state within 4 days. The body weight of the diabetic rats did not change during the 24 weeks, whereas the control rats continued to grow. The fasting blood glucose level increased two- to fourfold and glycosuria was present (Table 1). In a similar experiment using a higher dose of streptozotocin $(70 \mathrm{mg} / \mathrm{kg}$ ) a significant increase in the 7-S collagen concentration appeared earlier, but many of the rats died during the first 16 weeks (data not shown). 


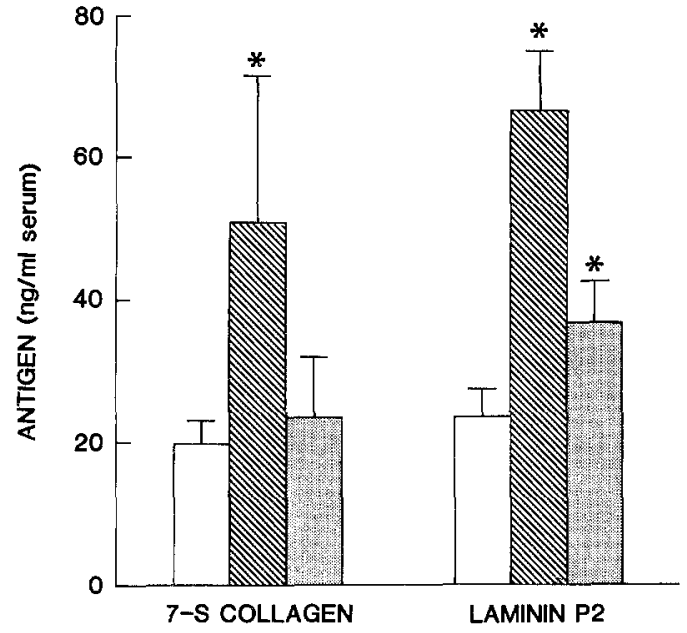

Fig. 1. Effect of insulin treatment on the serum concentration of 7-S collagen and laminin P2. The body weights and glycosuria levels were: $\square$ control rats $391 \pm 35 \mathrm{~g}$, no glycosuria; diabetic rats $158 \pm 26^{*} \mathrm{~g}$, $6.6 \pm 1.7^{*} \mathrm{~g} / 24 \mathrm{~h}$; and diabetic rats treated with insulin $321 \pm 26 \mathrm{~g}$, $3.1 \pm 1.3^{*} \mathrm{~g} / 24 \mathrm{~h}$. Values are expressed as mean $\pm \mathrm{SD}$. Significance levels were assessed as in Table $2: * p<0.001$ compared with the control rats

The effect of insulin treatment was studied in two independent experiments lasting 8 weeks (Table 2 and Fig.1). The diabetes was induced in both with a $70 \mathrm{mg} / \mathrm{kg}$ dose of streptozotocin. Treatment with either a low $(0.9 \mathrm{IU})$ or a high $(9 \mathrm{IU})$ daily dose of insulin prevented the increase in the concentration of 7-S collagen in the serum (Table 2). The weight gain of the diabetic rats was restored with insulin and the mean blood glucose level decreased, although glycosuria still existed (Table 2). In experiment 3 the concentration of laminin P2 was also measured (Fig. 1). Insulin treatment with the dose of 9 IU prevented the increase in 7-S collagen concentration as in the preceding experiment, but did not completely normalize the laminin P2 concentration.

\section{Discussion}

7-S collagen is a recently characterized basement membrane structure which is most probably formed when four molecules of type IV collagen are connected via their terminal regions $[4,5]$. It has been isolated after digestion with pepsin, trypsin or bacterial collagenase from all tissues containing basement membranes studied so far $[4,11]$. Purified antibodies against 7 -S collagen also reacted with almost all basement membranes of the body in immunofluorescence, indicating that $7-\mathrm{S}$ collagen is a common structural domain of type IV collagens [12]. Most of the antigenic activity of 7-S collagen in serum eluted in a single peak slightly in front of that observed with 7-S collagen isolated by proteases [6]. Type IV collagen has been located by immunoelectronmicroscopical methods in the lamina densa layer of basement membranes [3].
Laminin is a major non-collagenous glycoprotein in mouse tumour basement membrane [7]. It has been located in the lamina rara-layers of authentic basement membranes [3]. Disulphide-bonded regions of laminin can be isolated as distinct antigenic fragments P1 and P2 after digestion with pepsin [8]. A fragment similar to mouse laminin $\mathrm{P} 1$ can also be isolated from human placenta and kidney [13]. In serum, laminin P2 antigen appeared in the form of larger material, which may comprise intact laminin, and as smaller components similar in size to laminin P2 [6].

At present we can only suggest the origin of the serum antigens. Both 7-S collagen and laminin P2 are relatively resistant to proteases, and thus it is possible that they are formed and released into the circulation during normal basement membrane degradation. On the other hand, increases in their serum concentrations might reflect active synthesis of basement membrane proteins throughout the body.

A marked increase in serum concentrations of 7-S collagen and laminin P2 was found in the present cases of experimental diabetes. A marked decrease in serum concentrations has previously been found for both antigens with increasing age [6]. Also, a twofold increase in circulating 7-S collagen and a 15 -fold increase in laminin $\mathrm{P} 2$ antigen was measured in mice bearing a basement membrane producing tumour [6]. Thus the analysis of these antigens in serum obviously gives useful information on the metabolism of basement membranes.

Treatment with a low dose of insulin ( $0.9 \mathrm{IU} /$ day) prevented most of the increase in the 7-S collagen concentration, although mean blood glucose was clearly elevated and glycosuria as serious as in the untreated rats (Table 2). A high dose of insulin (9 IU/day) normalized the 7-S collagen concentration and prevented most of the increase in laminin $\mathbf{P} 2$ concentration, but glycosuria persisted (Table 2 and Fig. 1). Thus it was the treatment with insulin which seemed to correct the altered metabolism of basement membranes rather than any strict control over blood glucose and glycosuria. The role of insulin in basement membrane metabolism is further emphasized by the finding that genetically diabetic mice which had hyperglycaemia with hyperinsulinaemia [14] had no elevation in serum basement membrane antigens [6].

Acknowledgements. We gratefully acknowledge the expert technical assistance of Mrs. V. van Delden and Miss H. Reiter. We thank Professor KI Kivirikko and Dr. R. Timpl for helpful discussions. The work was supported by a grant of the Deutsche Forschungsgemeinschaft (project Ti 95/5).

\section{References}

1. Williamson JR, Kilo C (1977) Current status of capillary basement membrane disease in diabetes mellitus. Diabetes $26: 65-73$

2. Kolata GB (1979) Blood sugar and complications of diabetes. Sugar itself may damage cells. Science 203: 1098-1099

3. Risteli L, Risteli J (1981) Basement membrane research. Med Biol 59: 185-189 
4. Risteli J, Bächinger HP, Engel J, Furthmayr H, Timpl R (1980) 7-S collagen: characterization of an unusual basement membrane structure. Eur J Biochem 108: 239—250

5. Kühn K, Wiedemann H, Timpl R, Risteli J, Dieringer H, Voss T, Glanville RW (1981) Macromolecular structure of basement membrane collagens. Identification of 7-S collagen as a crosslinking domain of type IV collagen. FEBS Lett 125: 123-128

6. Risteli J, Rohde H, Timpl R (1981) Sensitive radioimmunoassay for 7-S collagen and laminin. Application to serum and tissue studies of basement membranes. Anal Biochem 113:372-378

7. Timpl R, Rohde H, Gehron Robey P, Rennard SI, Foidart JM, Martin GR (1979) Laminin - a glycoprotein from basement membranes. J Biol Chem 254: 9933-9937

8. Rohde H, Bächinger HP, Timpl R (1980) Characterization of pep$\sin$ fragments of laminin in a tumor basement membrane. Evidence for the existence of related proteins. Hoppe-Seyler's Z Physiol Chem 361: 1651-1660

9. Diem K, Lentner C (1970) Scientific tables, 7th ed, Ciba-Geigy, Basel, pp 172-173

10. Wallenstein S, Zucker CL, Fleiss JL (1980) Some statistical methods useful in circulation research. Circ Res 47:1-9
11. Dixit SN, Stuart JM, Seyer JM, Risteli J, Timpl R, Kang AH (1981) Type IV collagens: isolation and characterization of $7 \mathrm{~S}$ collagen from human kidney, liver and lung. Coll Rel Res 1: 549-556

12. Risteli J, Wick G, Timpl R (1981) Immunological characterization of the 7-S collagen domain of type IV collagens. Coll Rel Res 1: 419-432

13. Risteli L, Timpl R (1980) Isolation and characterization of pepsin fragments of laminin from human placenta and renal basement membranes. Biochem J 193: 749-755

14. Herberg L, Coleman DL (1977) Laboratory animals exhibiting obesity and diabetes syndromes. Metabolism 26:59-99

Received: 12 October 1981

and in revised form: 28 May 1982

Dr. J. Risteli

University of Oulu

Department of Clinical Chemistry

SF-90220 Oulu 22

Finland 